\title{
Molecular cloning, genomic organization and selective expression of bombesin receptor subtype 3 in the sheep hypothalamus and pituitary
}

\section{J C Whitley, C Moore, A S Giraud ${ }^{1}$ and A Shulkes}

University of Melbourne Department of Surgery, Austin and Repatriation Medical Centre, Austin Campus, Melbourne, Victoria, Australia

${ }^{1}$ University of Melbourne Department of Medicine, Western Hospital, Footscray, Victoria, Australia

(Requests for offprints should be addressed to J Whitley, University of Melbourne Department of Surgery, Austin and Repatriation Medical Centre, Austin Campus, Melbourne, Victoria,

Australia 3084)

\begin{abstract}
The bombesin receptor subtype 3 (BRS-3) is considered an orphan receptor as it has a low affinity for bombesin-like peptides and no identified natural ligand. We have reported a novel form of gastrin-releasing peptide (GRP) present in high abundance in the pregnant uterus of women and sheep. As BRS-3 was originally cloned from guinea pig uterus, we postulated that the uterine GRP-like peptide may be its natural ligand. We have therefore cloned the gene for the sheep homologue of BRS-3 and determined its distribution. The sheep BRS3 gene spans $4 \mathrm{kbp}$ and comprises three exons with intron-exon borders at positions similar to those observed for the human and mouse BRS-3 genes. The predicted amino acid sequence of ovine BRS-3 has approximately $85 \%$ identity with the human, mouse and guinea pig receptors. Highly conserved amino acids important in mediating receptor G-protein coupling to second messengers and important in ligand binding were found to be conserved in ovine BRS-3. One potentially important deviation was noted: ovine BRS-3 possesses an arginine residue at position 294 instead of a histidine residue as found in all other BRS-3. His ${ }^{294}$
\end{abstract}

was previously identified as important in ligandreceptor interactions while $\mathrm{Arg}^{294}$ was implicated in high ligand affinity. Thus ovine BRS-3 may have binding characteristics different from those of the human, mouse and guinea pig BRS-3 receptors. In the ewe, BRS-3 mRNA expression was detected in pituitary and hypothalamus but not in tissues of the pregnant uterus (endometrium, myometrium, chorioallantois or amnion). Nor was BRS-3 expression detected in the non-pregnant uterus or in testis. This pattern of BRS-3 expression is similar to that observed in the mouse but different from that observed in the human, rat and guinea pig. We conclude that there is no local interaction between uterine GRP-like peptide and BRS-3. However, the high expression of BRS-3 in the pituitary coupled with elevated circulating levels of this GRP-like peptide during pregnancy suggests an alternate pathway. Cloning of the ovine BRS-3 gene will permit a detailed functional analysis of this receptor in the sheep and its role in the mediation of action of uterine GRP.

Fournal of Molecular Endocrinology (1999) 23, 107-116

\section{INTRODUCTION}

The bombesin-like peptide family is made up of three groups of related peptides. The prototype peptides of each family - bombesin, ranatensin, phylolitorin - were initially isolated from frog skin but have also been found to be more widespread in mammals (Spindel et al. 1993). To date, two mammalian members of the bombesin-like peptide family have been identified, isolated, cloned and characterized: gastrin-releasing peptide (GRP) and neuromedin $\mathrm{B}(\mathrm{NMB})$, which are the mammalian homologues of bombesin and ranatensin respectively (Spindel et al. 1993). No mammalian member of the phylolitorin family has been identified so far.

GRP mRNA encodes a precursor of approximately 148 amino acids containing a signal sequence, GRP-(1-27) and a C-terminal extension 
peptide of variable length (Reeve et al. 1988). Proteolytic cleavage and C-terminal amidation generate the two major biologically active GRP forms, GRP-(1-27) and GRP-(18-27) (Reeve et al. 1988). However, other forms of undefined biological activity are also present in tumours (Miyake et al. 1994) and in specific uterine tissues (Giraud et al. 1993). We have shown that the pregnant uterus of women (Whitley et al. 1996) and sheep (Giraud et al. 1996) produces a GRP-like peptide that is larger and biochemically distinct from the wellcharacterized GRP-(1-27) and GRP-(18-27) found in the gut and brain. This finding of a novel GRP-like peptide in the pregnant uterus has also been reported by others (Xiao et al. 1996).

There are three types of mammalian bombesin receptors: bombesin receptor subtype 3 (BRS-3), GRP receptor (GRP-R) and NMB receptor (NMB-R) (see Kroog et al. 1995 for review). Ligands have been identified for GRP-R and NMB-R (GRP and NMB respectively) but to date no naturally occurring high-affinity ligand has been identified for BRS-3 (Ryan et al. 1998). This observation and the detection of BRS-3 mRNA expression in the pregnant uterus of women (Gorbulev et al. 1994, Whitley et al. 1996) and guinea pigs (Gorbulev et al. 1992) make the larger form of GRP found in the pregnant uterus an attractive candidate as the naturally occurring ligand for the BRS-3 receptor.

Our extensive studies in sheep have revealed that at late pregnancy GRP mRNA is the major product of the endometrium, accounting for $20 \%$ of all mRNA synthesized (Whitley et al. 1994). Temporal expression has been demonstrated with 5- and 24 -fold rises in peptide and mRNA respectively, observed during the luteal regression phase of the oestrous cycle (Whitley et al. 1998). During pregnancy, similar increases in peptide and mRNA are observed (Giraud et al. 1994). We hypothesized that BRS-3 was the cognate receptor for the uterine forms of GRP. In this study we have therefore characterized ovine BRS-3 in terms of its genomic organization, putative cDNA structure, distribution in the non-pregnant and pregnant uterus, pituitary, hypothalamus and testis. We have also compared these observations with studies in human, rat, mouse and guinea pig.

\section{METHODS}

\section{Isolation and nucleotide sequencing of sheep genomic BRS-3}

Half a million recombinant bacteriophages representing a library of EcoRI fragments of sheep genomic DNA purified from white blood cells and cloned into the $\lambda$ EMBL3 vector (supplied by Dr Tim Adams, Department of Veterinary Science, University of Melbourne) were screened by hybridization with full-length human BRS-3 cDNA (kindly supplied by J Battey, NIDHD, NIH, Bethesda, MD, USA and described in Fathi et al. 1993). Hybridization of ${ }^{32} \mathrm{P}$-labelled probe (prepared using Rediprime kit, Amersham, Castle Hill, NSW, Australia) and recombinant phage DNA on nitrocellulose membranes (Hybond C extra, Amersham) proceeded at $42{ }^{\circ} \mathrm{C}$ overnight in $30 \%$ formamide, $50 \mathrm{mM}$ sodium phosphate, $5 \times \mathrm{SSC}, 1 \mathrm{mM}$ sodium pyrophosphate, $5 \times$ Denhardt's solution, $50 \mu \mathrm{g} / \mathrm{ml}$ herring sperm DNA, $\mathrm{pH} 7 \cdot 0$. Unbound probe was removed by rinsing the membranes twice in $2 \times \mathrm{SSC}, 0 \cdot 1 \% \mathrm{SDS}$ and then twice for $15 \mathrm{~min}$ in fresh buffer, followed by two $15 \mathrm{~min}$ washes in $0 \cdot 1 \times \mathrm{SSC}, 0 \cdot 1 \% \mathrm{SDS}$ at $50{ }^{\circ} \mathrm{C}$. Following autoradiography of the washed membranes with Kodak X-OMAT AR X-ray film (Kodak, Coburg, Victoria, Australia) and two intensifying screens at $-80{ }^{\circ} \mathrm{C}$ for 7 days, 80 putative positive phage clones were observed. DNA from a single positive plaque was purified using the plate lysate method (Sambrook et al. 1989) and a restriction map constructed by Southern hybridization of restriction fragments using human BRS-3 cDNA as probe. A $4.4 \mathrm{kbp}$ PstI fragment was isolated, purified and ligated with vector pGEM 3Zf+ (Promega, Annandale, NSW, Australia). Double-stranded DNA of this recombinant plasmid was purified using Qiagen-tip 20 (Qiagen, Clifton Hill, Victoria, Australia) and the nucleotide sequence of the sheep DNA determined by automated DNA sequencing (ABI Prism, PerkinElmer, Foster City, CA, USA) with dye-labelled dideoxynucleotides and scanning laser detection. The $4.4 \mathrm{kbp}$ PstI fragment did not contain the last ten codons of the coding sequence. The corresponding DNA was subsequently isolated using a small SmaI-PstI fragment (nt 1254-1313, Fig. 1) derived from the $3^{\prime}$ end of the $4.4 \mathrm{kbp}$ PstI fragment as a probe in Southern hybridization of restriction fragments prepared from purified DNA of the original positive phage clone. A $0.8 \mathrm{kbp}$ SmaI-BamHI overlapping fragment was identified, purified and subcloned, and the nucleotide sequence determined as described above.

\section{RNA preparation}

Trizol reagent (Gibco BRL, Mulgrave, Victoria, Australia) was used to isolate approximately $1 \mathrm{mg}$ of total RNA from sheep tissue - non-pregnant endometrium, myometrium, hypothalamus, and pituitary; late pregnant (around 130 days) endometrium, 
gagtatctgagtgtcttggattgcctgccattctgctctgttcctctaccatctcattactagacgtaggcattagacgtgacaatcaa 90

$\begin{array}{lllllllllllllllll}M & S & Q & R & Q & P & Q & S & P & N & Q & T & L & 13\end{array}$

ctacatttgaactgagcagaagaaattttcaaggcataggctttagaagaaATGTCTCAAAGGCAGCCTCAGTCACCTAATCAGACTTTA 180

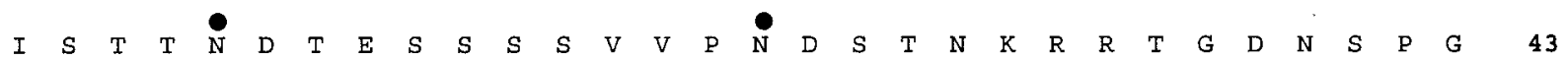

ATTTCAACCACAAATGACACAGAATCATCGAGCTCCGTCGTCCCTAATGATTCCACAAATAAAAGAAGgACCGGAGACAACTCTCCAGGA 270

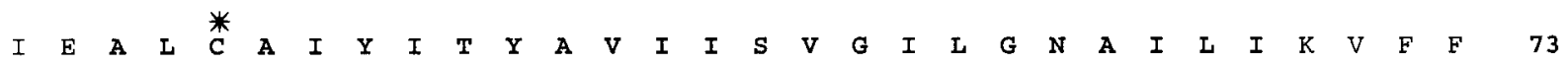

ATAGAAGCATTGTGTGCCATCTATATCACTTATGCCGTGATCATTTCAGTGGGCATCCTTGGAAATGCTATTCTCATCAAAGTCTTTTTC 360

$\begin{array}{llllllllllllllllllllllllllllllllllllll}K & T & K & S & M & Q & T & V & P & N & I & F & I & T & S & L & A & F & G & D & L & I & I & L & L & T & C & V & P & V & 103\end{array}$

AAGACCAAATCCATGCAAACAGTTCCCAATATTTTCATCACCAGCCTGGCTTTTGGAGATCTTTTACTTCTGCTAACTTGTGTGCCAGTC 450

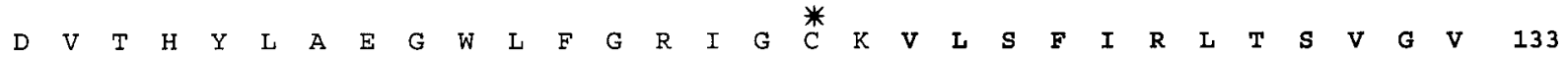

GATGTAACCCACTACCTGGCAGAGGGATGGCTGTTCGGAAGAATTGGATGTAAGGTGCTCTCTTTCATCCGGCTCACTTCTGTCGGTGTA 54O

$\begin{array}{lllllllllllllll}\text { S } & \text { V } & F & \text { T } & \text { L } & \text { T } & \text { I } & \text { L } & \text { S } & \text { A } & \text { D } & \text { R } & & & \\ 145\end{array}$

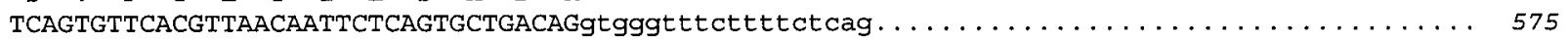

$\begin{array}{lllllllllllllllllll}Y & K & A & V & V & K & P & L & E & R & Q & P & P & N & A & I & L & K & 163\end{array}$

$\ldots \ldots$ (intron $1-1.4 \mathrm{kbp}$ ) ..tctagATACAAGGCAGTTGTGAAGCCCTTGGAGCGTCAGCCCCCCAATGCCATCCTGAAG 630

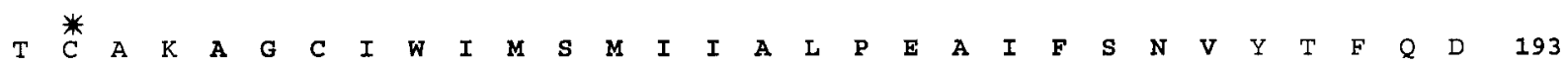

ACCTGTGCCAAAGCTGGCTGCATCTGGATCATGTCTATGATCATTGCTCTACCGGAGGCTATATTTTCAAATGTATATACTTTTCAAGAT 720

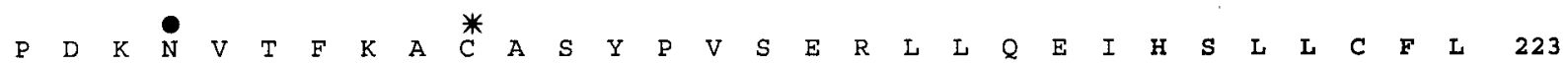

CCTGACAAAAATGTAACATTTAAAGCGTGTGCCTCTTACCCTGTTTCTGAGAGGCTCCTGCAAGAGATACATTCTCTTCTGTGCTTCTTA 810

$\begin{array}{lllllllllllllllllllllllllllllllllllllllll}V & F & Y & I & I & P & I & S & I & I & S & V & Y & Y & S & L & I & A & R & T & L & Y & K & S & T & I & N & I & P & T & 253\end{array}$

GTATTCTACATTATTCCACTTTCGATTATCTCTGTCTATTATTCTCTGATTGCTAGAACTCTTTACAAAAGCACCTTGAACATACCTACT 900

$\begin{array}{lllllllllllll}E & E & Q & R & H & A & R & K & Q\end{array}$

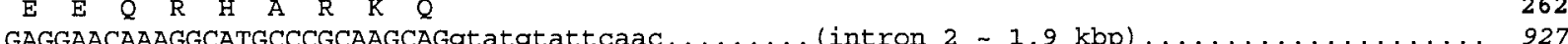

$\begin{array}{lllllllllllllllllllllllll}I & E & S & R & K & R & I & A & K & T & V & I & V & I & V & A & I & F & A & I & C & 283\end{array}$ ............... ctctctatagATTGAATCCCGGAAGCGAATTGCCAAAACAGTTCTGGTGCTGGTGGCTCTCTTTGCTCTCTGC 990

$\begin{array}{lllllllllllllllllllllllllllllllllll}\text { W } & L & P & N & \text { H } & \text { L } & \text { L } & Y & L & Y & R & S & F & T & S & Q & T & Y & M & D & S & S & T & V & H & I & F & V & T & I & 313\end{array}$ TGGTTGCCGAATCACCTTCTGTATCTCTACCGCTCATTCACTTCTCAAACCTATATGGACTCCTCTACCGTTCACTTATTTGTCACCATC 1080

$\begin{array}{llllllllllllllllllllllllllllllllllllllll}I & S & R & I & L & A & F & S & N & S & C & V & N & P & F & A & L & Y & W & L & S & N & T & F & Q & Q & H & F & K & A & 343\end{array}$ ATCTCTCGGATTCTGGCTTTCAGCAATTCTTGTGTAAACCCCTTTGCTCTTTACTGGCTGAGCAATACCTTCCAGCAGCATTTTAAAGCT I170

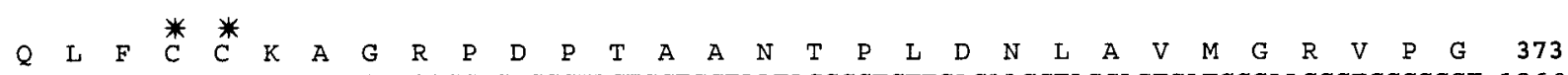
CAATTATTCTGTTGCAAGGCAGGGAGGCCTGACCCTACTGCTGCTAATACCCCTCTTGACAACCTAGCAGTGATGGGAAGGGTCCCGGGT 1260

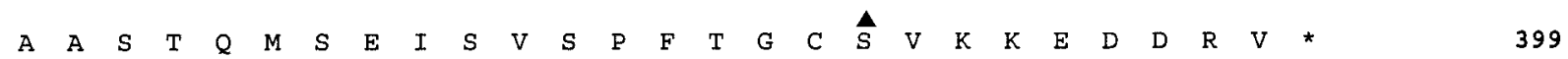
GCTGCAAGCACTCAGATGTCTGAAATTAGTGTGCCCCATTCACTGGCTGCAGTGTGAAGAAGGAAGATGACAGAGTCTAGcttttcaat 1350

taaaatggtatttttcctcccagagtgtctgttcaactctgagctatgcgtag

1405

FIGURE 1. Genomic organization, nucleotide sequence, and predicted amino acid sequence of the sheep BRS-3 gene. Nucleotide sequences corresponding to codons are shown in upper case. Numbering in italics corresponds to the transcribed sequence. Putative transmembrane domains are in bold lettering. Bold numbering refers to amino acids. Stars show the conserved cysteine residues. Circles show the location of potential sites for $N$-linked glycosylation. Triangles show the location of potential PKC phosphorylation sites. Restriction sites for endonucleases SmaI (5' CCCGGG 3') and PstI (5' CTGCAG 3') are underlined. GenBank Accession numbers for genomic sequence encompassing exons 1, 2 and 3 are AF108207, AF108208 and AF108209 respectively. GenBank Accession number for mRNA sequence is AF108210. 
myometrium, amnion, and chorioallantois; and ram testis - according to the manufacturer's instructions. PolyA+ RNA was purified from total RNA using biotinylated oligo dT complexed to magnetized streptavidin (PolyAT Tract; Promega).

\section{cDNA preparation and reverse transcription (RT)-PCR}

First-strand cDNA was synthesized from $250 \mathrm{ng}$ polyA+ RNA using SuperScript Reverse Transcriptase according to the manufacturer's instructions (Gibco BRL). A portion (one-twentieth) was used in PCR for detection of BRS-3 and $\beta$-actin gene expression. PCR consisted of $2 \cdot 5 \mathrm{U}$ HotStarTaq Polymerase (Qiagen), $1 \times$ HotStarTaq Polymerase buffer (supplied by the manufacturer and including $1.5 \mathrm{mM} \mathrm{MgCl}_{2}$ ), $0.2 \mathrm{mM} \mathrm{dNTPs}$ and $2 \mathrm{ng} / \mu \mathrm{l}$ each of the forward and reverse primers in a total volume of $50 \mu \mathrm{l}$. Primer pairs were designed to span an intron to ensure that PCR products were derived from cDNA and not contaminating genomic DNA. The primers used for detection of ovine BRS-3 gene expression were OUR37 (5' TTACCCTGTTTCTGAGAGGCTCCTGCA 3'; exon 2, nt 756-782 according to Fig. 1) and OUR38 (5' GTTTTGGCAATTCGCTTCCGGGATT 3'; exon 3, nt 956-932 according to Fig. 1). Primers used for the detection of ovine $\beta$-actin gene expression were $5^{\prime}$ TGGGAGCACATGGAGAA GATCTG $3^{\prime}$ and 5' CAGCACAGCCTGGAT GGCCACGTAC 3'. These were derived from partial coding sequence for Ovis aries $\beta$-actin mRNA (GenBank locus OAU39357) with exon boundaries deduced by comparison with the human $\beta$-actin gene sequence (GenBank locus HUMAC CYBB). Amplification consisted of a $15 \mathrm{~min}$ incubation at $95{ }^{\circ} \mathrm{C}$ followed by 30 ( $\beta$-actin) or 40 (BRS-3) cycles of $94{ }^{\circ} \mathrm{C}, 30 \mathrm{~s} ; 55^{\circ} \mathrm{C}, 30 \mathrm{~s} ; 72{ }^{\circ} \mathrm{C}, 30 \mathrm{~s}$ (FTS-960 Thermal Sequencer, Corbett Research, Mortlake, NSW, Australia). One-fifth of each reaction was subjected to electrophoresis through a $2 \%$ agarose gel and products visualized by staining with $0.5 \mu \mathrm{g} / \mathrm{ml}$ ethidium bromide prior to vacuum transfer to nylon membrane (Hybond $\mathrm{N}+$; Amersham). ${ }^{32}$ P-labelled oligonucleotides (BRS-3, 5' TGAGGAACAAAGGCATGCCCG CA 3', exon 2, nt 900-922 according to Fig. 1; $\beta$ actin, 5' CCCAAGGCCAACCGTGAGAAGAT GA $3^{\prime}$ ) were used for Southern hybridization of the blot using methods described in Whitley et al. (1996). When observed, the BRS-3 PCR product of approximately $200 \mathrm{bp}$ was size fractionated in $1 \cdot 2 \%$ low-melting agarose, purified away from the agarose using QIAEX silica slurry (Qiagen) and subject to ligation with pCR2.1 according to the manufac-

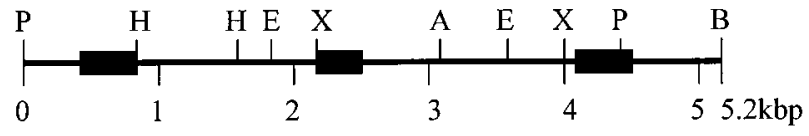

FIGURE 2. Genomic arrangement of the ovine BRS-3 gene. Position of recognition sites for restriction endonucleases AvaI (A), BamHI (B), EcoRI (E), HindIII (H), PstI (P) and XbaI (X) are shown. Exons are denoted as black boxes.

turer's instructions (Invitrogen, San Diego, CA, USA). Recombinant plasmid was purified and the nucleotide sequence of the insert determined as described above.

The putative cDNA sequence derived from the three exons observed in the BRS-3 gene sequence was confirmed by RT-PCR using primers designed to putative $5^{\prime}$ and $3^{\prime}$ untranslated sequence. The forward primer was OUR40 (5' GAGTATCTG AGTGTCTTGGATTG 3', nt 1-24 according to Fig. 1) and the reverse primer was OUR41 (5' CTACGCATAGCTCAGAGTTGAAC 3', nt 1383-1405 according to Fig. 1). A 1405 bp product was observed after two rounds of amplification and subcloned into vector pCR2. 1 as described above. A consensus sequence was obtained from three recombinant molecules to combat the possible introduction of errors during amplification using HotStarTaq Polymerase, which does not possess proof-reading activity.

\section{RESULTS}

\section{Isolation, restriction mapping and nucleotide sequence of ovine BRS-3}

Figure 2 shows a partial restriction map of the ovine BRS-3 gene defined using exon-specific fragments of human BRS-3 cDNA as probes in Southern hybridization. Figure 1 shows the nucleotide sequence of the exons with some adjacent intron sequence. This confirmed that the ovine BRS3 gene consisted of three exons separated by two introns of approximately 1.4 and $1.9 \mathrm{kbp}$. This arrangement is similar to that observed for the human (Gorbulev et al. 1994) and mouse (OhkiHamazaki et al. 1997a) BRS-3 genes except that the sheep BRS-3 gene introns are slightly larger $(1 \cdot 1$ and $1.4 \mathrm{kbp}$ for human gene, 1.2 and $1.5 \mathrm{kbp}$ for mouse gene). Intron/exon boundaries were inferred by alignment of the ovine sequence with the human gene and confirmed by RT-PCR using forward and reverse primers designed to sequence within the $5^{\prime}$ and $3^{\prime}$ untranslated regions respectively. Intron 1 interrupts codon $\mathrm{Arg}^{145}$ and intron 2 lies between 
$\mathrm{Gln}^{262}$ and $\mathrm{Ile}^{263}$. Both predicted splice junctions adhered to the general rule for donor and acceptor consensus sequences in which the $5^{\prime}$ border of an intron starts with a GT and the $3^{\prime}$ border terminates with an AG (Breathnach \& Chambon 1981). The boundaries of the second intron were confirmed by analysis of the RT-PCR product generated by primers OUR37 (exon 2) and OUR38 (exon 3). The nucleotide sequence of the $201 \mathrm{bp}$ product was determined in both directions and agreed with the predicted junction. No promoters for transcription initiation were found when the nucleotide sequence was analysed using a consensus-based weight matrix for POLII recognition sites (PROSCAN; Prestridge 1995). This is probably due to a lack of upstream sequence (273 bp from the ATG start site). Gorbulev et al. (1994) analysed approximately $1 \mathrm{kbp}$ of upstream sequence and were still unable to clearly identify a putative promoter site for the human BRS-3 gene. Codon 1 (nt 142, Fig. 1) of the BRS-3 gene product was assigned on the basis of amino acid homology to the human, mouse and guinea pig BRS-3 proteins. The ATG within GAAGAATGT is a poor match to the GCC (A/G) CCATGG Kozak consensus sequence for translation initiation in vertebrates (Kozak 1987) but is almost identical to the human sequence GAAG AAATGG. No polyadenylation signal could be identified, probably due to insufficient downstream sequence.

\section{Proposed amino acid sequence of ovine BRS-3}

The coding region of the ovine BRS-3 receptor predicts a protein of 399 amino acids - identical in length to the human, mouse and guinea pig BRS-3 receptors (Fig. 3). Ovine BRS-3 has $86 \%$ identity with the human receptor and $84 \%$ identity with the mouse and guinea pig receptors. Hydropathy analysis clearly showed seven hydropathic regions consistent with seven transmembrane domains, which are typical of the G-protein-coupled receptor superfamily (GPCRs).

Three potential sites for $N$-linked glycosylation (NXS/T) could be identified in the extracellular $\mathrm{N}$-terminal domain of ovine BRS-3 $\left(\mathrm{Asn}^{10}, \mathrm{Asn}^{18}\right.$, $\left.\mathrm{Asn}^{29}\right)$ with a fourth site $\left(\mathrm{Asn}^{197}\right)$ located in the second extracellular domain (designated by circles in Fig. 1 and individually boxed in Fig. 3). A potential protein kinase $\mathrm{C}$ ( $\mathrm{PKC}$ ) phosphorylation site conserved amongst all bombesin receptors was also found in the third intracellular domain of ovine BRS-3 (designated by a triangle in Fig. 1 and a broken line box in Fig. 3). The C-terminal domain possessed a second potential PKC site $\left(\mathrm{Ser}^{391}\right.$, triangle in Fig. 1, broken line box in Fig. 3) as well as 11 Ser or Thr residues which could be targets for phosphorylation by other kinases. Residues Asp ${ }^{93}$, $\mathrm{Cys}^{120}, \mathrm{Arg}^{145}, \mathrm{Cys}^{203}, \mathrm{Ala}^{260}$ and $\mathrm{Asn}^{326}$ within the sequence $\mathrm{NPX}_{2-3} \mathrm{Y}$, are highly conserved among all GPCRs and were also present in ovine BRS-3 (cysteines designated by stars in Fig. 1 and all other residues vertically boxed in Fig. 3). A putative palmitoylation site is observed, $\mathrm{Cys}^{347} \mathrm{Cys}^{348}$ (shaded in Fig. 3).

\section{Tissue distribution of ovine BRS-3 expression}

RT-PCR of polyA+ purified RNA was used for detection of BRS-3 and $\beta$-actin mRNA expression (Fig. 4). $\beta$-Actin PCR product was observed for all cDNA samples tested and confirmed by Southern hybridization using an oligonucleotide to a sequence situated between the forward and reverse primers. No BRS-3 PCR product could be detected in sheep testis, pregnant or non-pregnant endometrium or myometrium, nor in the uteroplacental membranes - amnion and chorioallantois. However, BRS-3 PCR products were observed for cDNA prepared from pituitary and hypothalamus and confirmed by Southern hybridization using an internal oligonucleotide probe and by nucleotide sequence analysis.

\section{DISCUSSION}

BRS-3 was first reported in 1992 (Gorbulev et al. 1992) and despite extensive characterization of the receptor (Mantey et al. 1997, Ryan et al. 1998) a ligand has not yet been identified. Use of a newly described high-affinity synthetic ligand has shown that this receptor has a unique pharmacology compared with other receptors (Mantey et al. 1997). Renewed interest in BRS-3 has occurred recently with description of the BRS-3 knockout mouse (Ohki-Hamazaki et al. 1997b) and observation that deletion of the BRS-3 gene results in a host of disturbances in energy metabolism. Our interest in the bombesin family lies in our findings that expression of a GRP-related peptide in the endometrium is altered and apparently regulated during different reproductive states and cycles (Giraud et al. 1993, 1994, 1996, Whitley et al. 1994, 1996, 1998). Biochemical characterization of uterine GRP has revealed a molecule that is larger than, and distinct from, GRP-(1-27) (Giraud et al. 1996). We have hypothesized that this molecule may be the ligand for BRS-3 and that BRS-3 mediates the actions of this molecule in the uterus. The results presented here demonstrate that ovine BRS-3 is not expressed in the pregnant or non-pregnant uterus 
and therefore could not mediate any local actions of uterine GRP.

Most features of the predicted amino acid sequence of ovine BRS-3 conform to those described generally for GPCRs and specifically for bombesin receptors and have been described in detail elsewhere (Strader et al. 1994, Akeson et al. 1997, Ohki-Hamazaki et al. 1997a). There are four consensus sites for $N$-linked glycosylation in ovine BRS-3 which may be associated with ligand affinity and coupling to $\mathrm{G}$-proteins as suggested for murine GRP-R by Kusui et al. (1994). Also important in

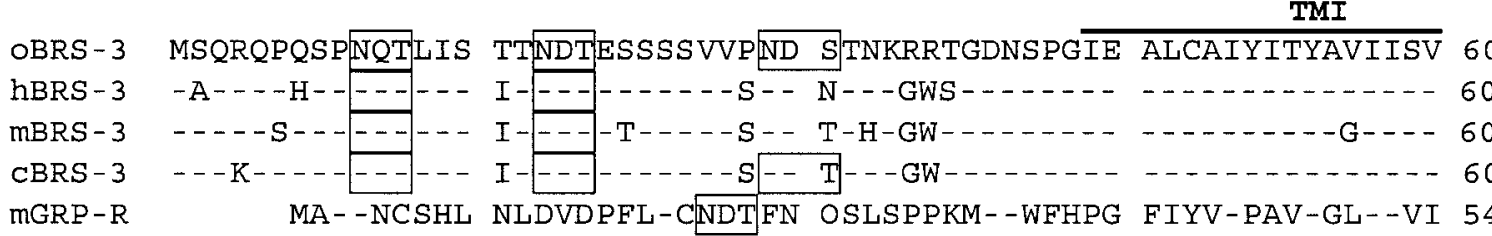

iI

TMII

e1

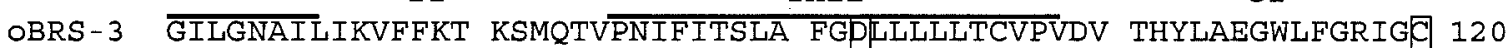

hBRS -3

mBRS -3

CBRS -3

MGRP-R

GILGNAILIKVFFK KSMQTVPNIFITSLA FGPLLLLLICVPVDV THYLAEGWLFGRIGC 120

120

-

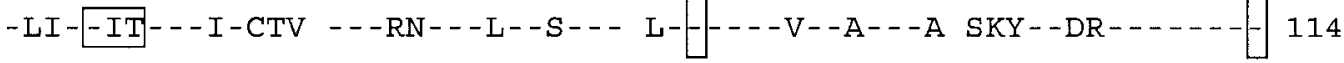

TMIII i2

TMIV

OBRS-3 KVLSFIRLTSVGVSV FTLTILSAIRYKAVV KPLERQPPNAILKTC AKAGCIWIMSMIIAL 180

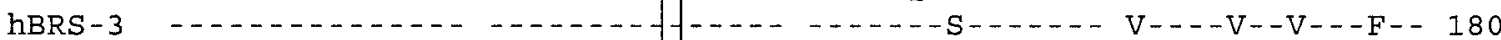

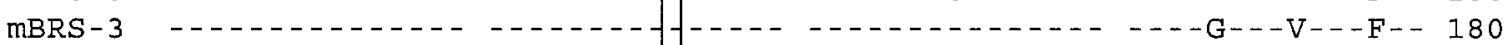
CBRS-3 - 3 MGRP-R

$-\mathrm{LIP}-\mathrm{Q}$ A- - -

R-MDI-ASH-LM-I- L- -AL---V--LL-I 174

OBRS -3

$\overline{\text { PEAIFSNVYTFQDPD KNVTFKAFASYPVSE RLLQEIHSLLCFLVF YIIPLSIISVYYSLI }} 240$

hBRS - 3

$---1--\mathrm{R}-\mathrm{N}-\mathrm{M}-\mathrm{ES}-\mathrm{T}-\cdots-\mathrm{K}$ K-

$-Q--N$ R --- ES-N-D-I-

-...-...-. 240

mBRS -3

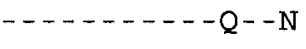

$-\mathrm{M}-\mathrm{SEW}-\mathrm{F}-\mathrm{F}-\mathrm{C}$

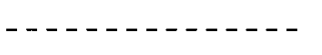

CBRs -3

- - - - - H-LR- -N

$\mathrm{T}-\mathrm{Q}-\mathrm{-}-\mathrm{IS}$

$-\mathrm{P}-\mathrm{H}-\mathrm{N}$

$\mathrm{K}-\cdots-\mathrm{A}-\mathrm{S}-\mathrm{C}$

240

mGRP-R

i3

TMVI

e3

OBRS -3

hBRS -3

mBRS -3

CBRS -3

MGRP-R

ARTLYKSTLNIPTEE QRHARKQIESTRKKKKRTA KTVLVLVALFALCWL PNHLLYLYRSFTSQT 300

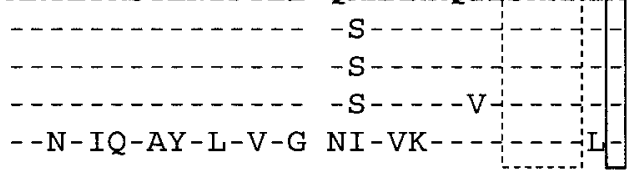

R-...............-.-. - - 300

R

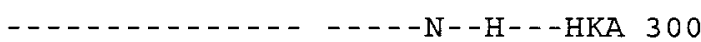

OBRS -3

TMVII

YNSSTVHLFVTIIS RILAFSNSCYNPFAL YWLSNTFQQHFKAQL FCCKAGRPDPTA. . . 357

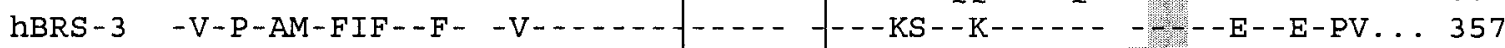

mBRS-3 -ANH-D-PFVII-F- -V-..... . .

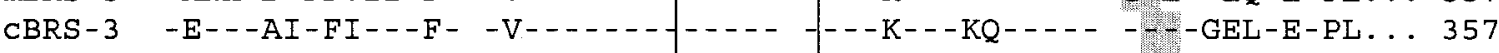

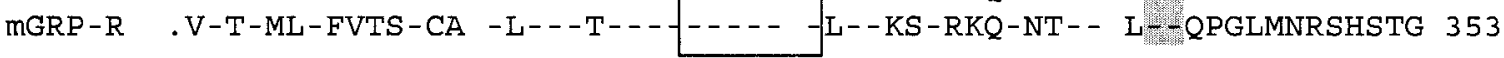

OBRS-3 .ANTPLDNLAVMGRV PGAASTQMSEISVSPFTGC SVKKEDDRV 399

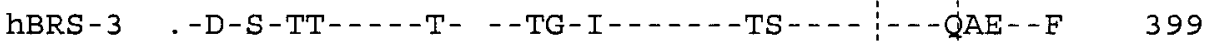

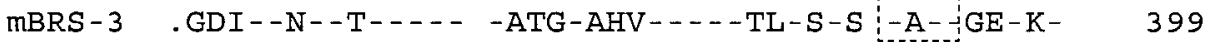

CBRS-3 . -A---NS--.-.- S-TEN-HI---G-AS-I-R PM---EN-- 399

MGRP-R RST-CMTSFKSTNPS ATFSLINRNICHEGYV 


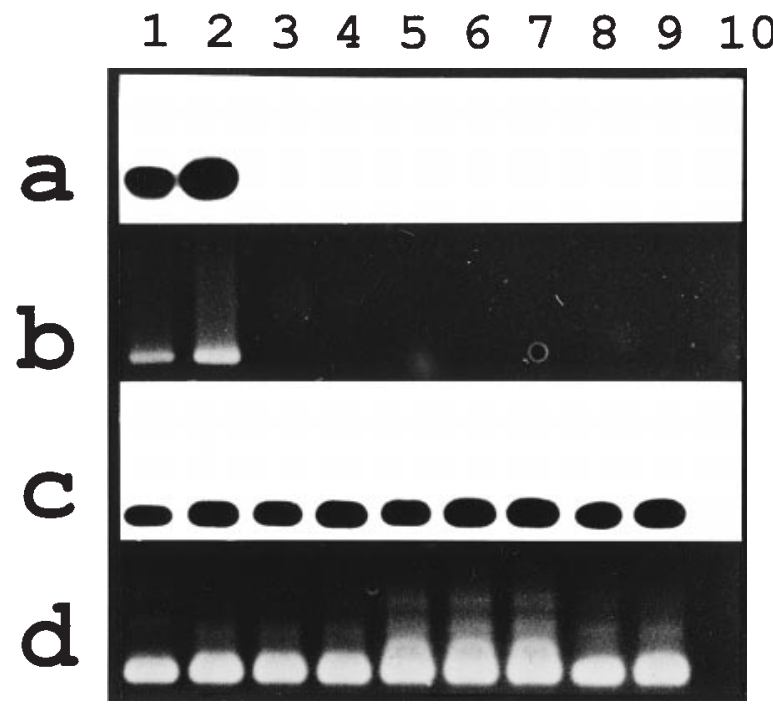

FIGURE 4. RT-PCR for detection of BRS-3 and $\beta$-actin mRNA in various ovine tissues. cDNA was prepared from pituitary (1), hypothalamus (2), testes (3), endometrium (4) and myometrium (5) from non-pregnant sheep; endometrium (6), myometrium (7), amnion (8) and chorioallantois (9) from late term pregnant sheep or from water (10). Products from RT-PCR for BRS-3 mRNA (panels a and b) and for $\beta$-actin mRNA (panels $c$ and $d$ ) were detected by agarose gel electrophoresis and ethidium bromide staining (panels $\mathrm{b}$ and $\mathrm{d}$ ) and by Southern hybridization using gene-specific oligonucleotide probes (panels a and c).

mediating receptor G-protein coupling to second messengers are other highly conserved amino acids: $\mathrm{Ala}^{270}$ within the third intracellular loop and $\mathrm{Arg}^{145}$ within the motif DRY that is completely conserved amongst all bombesin receptors. The motif $\mathrm{NPX}_{2-3} \mathrm{Y}$ within the seventh transmembrane domain is highly conserved amongst the GPCRs and the sequence NPFALY is completely conserved for all bombesin receptors. The Tyr residue within this motif has been shown to be required for internalization of the $\beta 2$-adrenergic receptor (Barak et al. 1994) but mutation of this Tyr had no effect on internalization of GRP-R (Slice et al. 1994). A consensus sequence for $\mathrm{PKC}$ phosphorylation is $\mathrm{Ser}^{265}$ distal to the third intracellular loop in ovine BRS-3 and completely conserved amongst all bombesin receptors.

Highly conserved cysteine residues found within the first and second extracellular loops of ovine BRS-3 ( $\mathrm{Cys}^{120}$ and $\mathrm{Cys}^{203}$ ) are conserved amongst all bombesin receptors and may be important for the formation of the ligand-binding site as demonstrated for $\beta$-adrenergic receptor (Strader et al. 1994). Other cysteine residues conserved amongst all bombesin receptors are found within transmembrane domains II, VI and VII (Cys ${ }^{100}$, $\mathrm{Cys}^{283}$ and $\mathrm{Cys}^{324}$ ) and $\mathrm{Cys}^{48}$ and $\mathrm{Cys}^{165}$ are conserved amongst all BRS-3.

A number of features have been identified in the cytoplasmic C-terminus of many GPCRs that appear to be involved in the mediation of receptor internalization (or sequestration). These include a putative palmitoylation site, PKC consensus sequence and multiple Ser and $\mathrm{Thr}$ residues (Strader et al. 1994). These can all be identified in the C-terminus of the predicted ovine BRS-3. There is a putative palmitoylation site (Cys Cys) at $\mathrm{Cys}^{347}$ that is present for all bombesin receptors. A site for phosphorylation by PKC is well conserved amongst GRP-R ( $\mathrm{Thr}^{362}$ within the consensus TSFK) and NMB-R and has been shown to be partially responsible for mediating internalization of GRP-R (Benya et al. 1993) but is absent for all BRS-3. For ovine BRS-3, the sequence SVKK near the C-terminus at Ser $^{391}$ fits the PKC phosphorylation consensus predicted by Kennelly \& Krebs (1991), but is not well conserved amongst all BRS-3 receptors and is absent in guinea pig BRS-3 (Fig. 3). There are $11 \mathrm{Ser} / \mathrm{Thr}$ residues in the intracellular C-terminus of ovine BRS-3 similar to all other bombesin receptors and reported to be important in GRP-R internalization (Benya et al. 1993).

Despite the high amino acid sequence homology, there is one potentially important difference in ovine BRS-3 when compared with human, mouse and guinea pig BRS-3. Akeson et al. (1997) hypothesized

FIGURE 3. Comparison of BRS-3 protein sequences from sheep (oBRS-3), human (hBRS-3), mouse (mBRS-3) and guinea pig (cBRS-3) and mouse GRP-R (mGRP-R) was performed using the CLUSTAL W sequence alignment program (http://dot.imgen.bcm.tmc.edu:9331/multi-align/multi-align.html, Thompson et al. 1994). Amino acids that differ from the ovine BRS-3 sequence are shown. Putative transmembrane (TM), extracellular(e) and intracellular(i) domains are indicated. The BRS-3 protein sequences were obtained from GenBank: loci Z97362, X76498, L08893 (human, all identical), AB010280 (mouse) and X67126 (guinea pig), as was mouse GRP-R at locus MUSGRPBOM. NXT/S indicates putative sites for $N$-linked glycosylation. Amino acids conserved in most GPCRs are boxed. Consensus sequences for possible phosphorylation by PKC are surrounded by a dashed box. Putative palmitolyation sites are indicated by shaded CC. Four amino acids in GRP-R necessary for high affinity ligand binding are indicated * (Akeson et al. 1997). 
that amino acids essential for high-affinity bombesin binding would be conserved amongst all known GRP-R, NMB-R and BB4 (an amphibian receptor for $\left[\mathrm{Phe}^{13}\right]$ bombesin; Nagalla et al. 1995) and would diverge in the BRS-3 sequences. Transfection of mammalian cells with various mutated GRP-R revealed four amino acids in mouse GRP-R required for high-affinity agonist binding and conserved in all GRP-R but not BRS-3. One of these residues, $\mathrm{Arg}^{294}$, is found in the ovine BRS-3 amino acid sequence but not in human, mouse or guinea pig BRS-3, which possess His ${ }^{294}$. Akeson et al. (1997) constructed a mutated human BRS-3 with the H294R substitution (as well as R127Q) and showed increased affinity for GRP and bombesin. This suggests that ovine BRS-3 may have different binding characteristics compared with other BRS-3 and will be ascertained by mutagenesis and binding experiments.

Unlike GRP-R, the tissue-specific expression of BRS-3 mRNA appears to be highly speciesdependent. Abundant expression is detected in the rat testis (Fathi et al. 1993) but barely detected in the mouse testis (Ohki-Hamazki et al. 1997a) and not found in sheep testis (Fig. 4). BRS-3 mRNA expression has been detected in the pregnant uterus of guinea pig (Gorbulev et al. 1992) and women (Gorbulev et al. 1994, Whitley et al. 1996) but not in mouse (Ohki-Hamazaki et al. 1997a) or sheep (this study). Weak expression of BRS-3 mRNA was detected in guinea pig brain (area not specified) (Gorbulev et al. 1992), while in mouse brain it was localized to hypothalamic regions (Ohki-Hamazaki et al. 1997a) but expression was not detected in rat brain (Fathi et al. 1993). Expression of BRS-3 mRNA is restricted compared with other mammalian bombesin receptors. GRP-R and NMB-R are much more widely expressed in rat, mouse and human tissues as well as lung carcinoma cell lines (Fathi et al. 1996, Toi-Scott et al. 1996), cultured human bronchial epithelial cells (DeMichele et al. 1994), prostate carcinoma cell lines (Aprikian et al. 1996) and prostate carcinoma tissue (Bartholdi et al. 1998). The only reported exception appears to be individual nasal mucosa samples where the frequency of BRS-3 mRNA detection was equal to that of NMB-R and more than double the frequency of GRP-R mRNA detection (Ali et al. 1996).

The initial isolation of BRS-3 cDNA from guinea pig pregnant uterus and the observation that BRS-3 expression was restricted largely to the pregnant uterus led to the proposal that BRS-3 was a uterinespecific bombesin receptor (Gorbulev et al. 1992). Lack of a naturally occurring ligand for BRS-3 and detection of a novel GRP-like peptide in the pregnant sheep uterus (Fraser et al. 1992, Giraud et al.
1993) led to the attractive proposition that BRS-3 could mediate the function of uterine GRP. The findings presented in this study that BRS-3 is not expressed in the sheep uterus dispel this hypothesis. This does not mean, however, that the novel uterine GRP is not the natural ligand for BRS-3. It is possible that the pituitary (which is a major site of BRS-3 expression) is the target tissue for uterine GRP as very high blood levels are found in both the maternal and fetal plasmas (Giraud et al. 1993, Whitley et al. 1996). Several reports have indicated that bombesin-like peptides have a physiological role in the anterior pituitary with effects on the release of growth hormone and prolactin (Kentroti \& McCann 1996), adrenocorticotrophic hormone ( $\mathrm{Au}$ et al. 1997) and thryroid-stimulating hormone (Santos et al. 1995) - hormones known to be involved in energy metabolism and with secretion rates that change markedly during pregnancy. Interestingly, the major phenotypic effects observed in BRS-3 knockout mice are changes in energy metabolism and adiposity (Ohki-Hamazaki et al. 1997b). Potential interaction between the novel form of uterine GRP and the pituitary BRS-3 will be of particular interest with regard to possible metabolic effects. These studies are in progress.

\section{ACKNOWLEDGEMENTS}

This work was supported by the National Health and Medical Research Council of Australia and the Austin Hospital Medical Research Foundation.

\section{REFERENCES}

Akeson M, Sainz E, Mantey SA, Jensen RT \& Battey JF 1997 Identification of four amino acids in the gastrin-releasing peptide receptor that are required for high affinity agonist binding. Fournal of Biological Chemistry 272 17405-17409.

Ali M, Gawin AZ \& Baraniuk JN 1996 Effects of bombesin family peptides and antagonists on guinea pig nasal mucosal secretion. Fournal of Pharmacology and Experimental Therapeutics 276 1266-1271.

Aprikian AG, Han K, Chevalier S, Bazinet M \& Viallet J 1996 Bombesin specifically induces intracellular calcium mobilization via gastrin-releasing peptide receptors in human prostate cancer cells. Fournal of Molecular Endocrinology 16 297-306.

Au CL, Canny BJ, Farnworth PG \& Giraud AS 1997 Bombesin regulation of adrenocorticotropin release from ovine anterior pituitary cells. Peptides 18 995-1000.

Barak LS, Tiberi M, Freedman NJ, Kwatra MM, Lefkowitz RJ \& Caron MG 1994 A highly conserved tyrosine residue in $\mathrm{G}$ protein-coupled receptors is required for agonistmediated beta 2-adrenergic receptor sequestration. Fournal of Biological Chemistry 269 2790-2795.

Bartholdi MF, Wu JM, Pu H, Troncoso P, Eden PA \& Feldman RI 1998 In situ hybridization for gastrin-releasing peptide receptor (GRP receptor) expression in prostatic carcinoma. International Fournal of Cancer 79 82-90. 
Benya RV, Fathi Z, Battey JF \& Jensen RT 1993 Serines and threonines in the gastrin-releasing peptide receptor carboxyl terminus mediate internalization. Fournal of Biological Chemistry 268 20285-20290.

Breathnach R \& Chambon P 1981 Organization and expression of eucaryotic split genes coding for proteins. Annual Review of Biochemistry 50 349-383.

DeMichele MA, Davis AL, Hunt JD, Landreneau RJ \& Siegfried JM 1994 Expression of mRNA for three bombesin receptor subtypes in human bronchial epithelial cells. American Gournal of Respiratory Cell and Molecular Biology 11 66-74.

Fathi Z, Corjay MH, Shapira H, Wada E, Benya R, Jensen R, Viallet J, Sausville EA \& Battey JF 1993 BRS-3: a novel bombesin receptor subtype selectively expressed in testis and lung carcinoma cells. Fournal of Biological Chemistry 268 5979-5984.

Fathi Z, Way JW, Corjay MH, Viallet J, Sausville EA \& Battey JF 1996 Bombesin receptor structure and expression in human lung carcinoma cell lines. Fournal of Cellular Biochemistry 24 (Suppl) 237-246.

Fraser M, Carter AM, Challis JRG \& McDonald TJ 1992 Gastrin-releasing peptide immunoreactivity is present in ovine amniotic fluid and fetal and maternal circulations. Endocrinology 131 2033-2035.

Giraud A, Parker L, Taupin D, Hardy K \& Shulkes A 1993 Mammalian bombesin as a hormone in ovine pregnancy: ontogeny, origin, and molecular forms. American Fournal of Physiology 265 E866-E873.

Giraud A, Salamonsen L, Whitley J \& Shulkes A 1994 A peptide related to gastrin-releasing peptide is synthesised and secreted by the ovine endometrium in early pregnancy. Endocrinology 135 2806-2809.

Giraud A, Whitley J, Shulkes A \& Parker L 1996 The pregnant ovine endometrium constituitively expresses and secretes a highly stable bombesin-like peptide, which shares C-terminal sequence but differs structurally from gastrin-releasing peptide. Biochimica et Biophysica Acta 1296 189-197.

Gorbulev V, Akhundova A, Buchner H \& Fahrenholz F 1992 Molecular cloning of a new bombesin receptor subtype expressed in uterus during pregnancy. European Fournal of Biochemistry 208 405-410.

Gorbulev V, Akhundova A, Grzeschik KH \& Fahrenholz F 1994 Organization and chromosomal localization of the gene for the human bombesin receptor subtype expressed in pregnant uterus. FEBS Letters 340 260-264.

Kennelly PJ \& Krebs EG 1991 Consensus sequences as substrate specificity determinants for protein kinases and protein phosphatases. Fournal of Biological Chemistry 266 15555-15558.

Kentroti S \& McCann SM 1996 Role of dopamine in the inhibitory control of growth hormone and prolactin release by gastrin-releasing peptide. Brain Research Bulletin 39 201-204.

Kozak M 1987 An analysis of 5'-noncoding sequences from 699 vertebrate messenger RNAs. Nucleic Acids Research 15 8125-8148.

Kroog GS, Jensen RT \& Battey BF 1995 Mammalian bombesin receptors. Medical Research Reviews 15 389-417.

Kusui T, Benya RV, Battey JF \& Jensen RT 1994 Glycosylation of bombesin receptors: characterization, effect on binding, and G-protein coupling. Biochemistry $\mathbf{3 3}$ 12968-12980.

Mantey SA, Weber HC, Sainz E, Akeson M, Ryan RR, Pradhan TK, Searles RP, Spindel ER, Battey JF, Coy DH \& Jensen RT 1997 Discovery of a high affinity radioligand for the human orphan receptor, bombesin receptor subtype 3 , which demonstrates that it has a unique pharmacology compared with other mammalian bombesin receptors. Fournal of Biological Chemistry 272 26062-26071.
Miyake Y, Kodama T \& Yamaguchi K 1994 Pro-gastrinreleasing peptide (31-98) is a specific tumor marker in patients with small cell lung carcinoma. Cancer Research 54 2136-2140.

Nagalla SR, Barry BJ, Creswick KC, Eden P, Taylor JT \& Spindel ER 1995 Cloning of a receptor for amphibian $\left[\mathrm{Phe}^{13}\right]$ bombesin distinct from the receptor for gastrinreleasing peptide: Identification of a fourth bombesin receptor subypte (BB4). Proceedings of the National Academy of Sciences of the USA 92 6205-6209.

Ohki-Hamazaki H, Wada E, Matsui K \& Wada K $1997 a$ Cloning and expression of the neuromedin $\mathrm{B}$ receptor and the third subtype of bombesin receptor genes in the mouse. Brain Research 762 165-172.

Ohki-Hamazaki H, Watase K, Yamamoto K, Ogura H, Yamano M, Yamada K, Maeno H, Imaki J, Kikuyama S, Wada E \& Wada K $1997 b$ Mice lacking bombesin receptor subtype-3 develop metabolic defects and obesity. Nature 390 165-169.

Prestridge DS 1995 Predicting Pol II promoter sequences using transcription factor binding sites. Fournal of Molecular Biology 249 923-932.

Reeve JR Jr, Cuttitta F, Vigna SR, Shively JE \& Walsh JH 1988 Processing of mammalian preprogastrin-releasing peptide. Annals of the New York Academy of Sciences $\mathbf{5 4 7}$ 21-29.

Ryan RR, Weber HC, Hou W, Sainz E, Mantey SA, Battey JF, Coy DH \& Jensen RT 1998 Ability of various bombesin receptor agonists and antagonists to alter intracellular signaling of the human orphan receptor BRS-3. Fournal of Biological Chemistry 273 13613-13624.

Sambrook J, Fritsch EF \& Maniatis T 1989 Molecular Cloning: a Laboratory Manual, edn 2. Cold Spring Harbor, NY: Cold Spring Harbor Laboratory Press.

Santos CV, Pazos-Moura CC \& Moura EG 1995 Effect of gastrin-releasing peptide (GRP) and GRP antagonists on TSH secretion from rat isolated pituitaries. Life Sciences $\mathbf{5 7}$ 911-915.

Slice LW, Wong HC, Sternini C, Grady EF, Bunnett NW \& Walsh JH 1994 The conserved NPXnY motif present in the gastrin-releasing peptide receptor is not a general sequestration sequence. Fournal of Biological Chemistry 269 21755-21761.

Spindel ER, Giladi E, Segerson TP \& Nagalla S 1993 Bombesin-like peptides: of ligands and receptors. Recent Progress in Hormone Research 48 365-391.

Strader CD, Fong TM, Tota MR, Underwood D \& Dixon RA 1994 Structure and function of $\mathrm{G}$ protein-coupled receptors. Annual Review of Biochemistry 63 101-132.

Thompson JD, Higgins DG \& Gibson TJ 1994 CLUSTAL $\mathrm{W}$ : improving the sensitivity of progressive multiple sequence alignment through sequence weighting, position-specific gap penalties and weight matrix choice. Nucleic Acids Research 22 4673-4680.

Toi-Scott M, Jones CL \& Kane MA 1996 Clinical correlates of bombesin-like peptide receptor subtype expression in human lung cancer cells. Lung Cancer 15 341-354.

Whitley J, Giraud A, Salamonsen L, Grant P \& Shulkes A 1994 Expression of gastrin-releasing peptide during pregnancy. Proceedings of the 37th Annual Meeting of the Endocrine Society of Australia, Brisbane, 25-28 September, Abstract 55. The Endocrine Society of Australia.

Whitley JC, Giraud AS \& Shulkes A 1996 Expression of gastrin-releasing peptide (GRP) and GRP receptors in the pregnant human uterus at term. Fournal of Clinical Endocrinology and Metabolism 81 3944-3950.

Whitley JC, Shulkes A, Salamonsen LA, Vogiagis D, Familari M \& Giraud AS 1998 Temporal expression and cellular 
localization of a gastrin-releasing peptide-related gene in ovine uterus during the oestrous cycle and pregnancy.

Fournal of Endocrinology 157 139-148.

Xiao Q, Challis JR, Fraser M, Wlodek ME, Thorburn GD, Cuttita F, Hill DJ, St-Pierre S, Spindel ER \& McDonald TJ 1996 Locations and molecular forms of gastrin-releasing peptide-like immunoreactive entities in ovine pregnancy. Peptides 17 489-495.

RECEIVED 5 January 1999

REVISED MANUSCRIPT RECEIVED 22 March 1999 